\title{
THE ROLE OF RESEARCH AND TECHNOLOGY IN SHAPING A SUSTAINABLE FRUIT INDUSTRY: EUROPEAN ADVANCES AND PROSPECTS ${ }^{1}$
}

\author{
SILVIEROSANSAVINI ${ }^{2}$
}

Dipartimento di Colture Arboree, Università di Bologna - viale Fanin 46 - 40127 Bologna

\section{Foreword}

There is a key question facing the fruit industry today, and tomorrow, and a look at the factors involved is a necessary adjunct to the answer we eventually come up with. Indeed, our modern fruit industry needs on one hand to blend and make compatible, while keeping a competitive edge in a global marketplace, its intensive, specialized production systems with the stewardship of its ecosystems by enhancing biological diversity, cutting energy inputs and reducing environmental impact. These issues on the other hand must also be responsible to the increasingly pressing demands of consumers for greater produce selectivity, quality, safety and pipeline transparency. The question is thus how to manage these competing demands and deliver the best fruit research that money can buy.

Needless to say, these issues, and increasingly creative responses to them, have for years now been at the very top of the research agenda in the more advanced economies. At the same time, however, growers have been left in a quandary due mainly to uncertainties underlying their organizational inefficiencies and inadequate information in regard to both consumer trends and the consequences deriving from market globalisation. Thus, the ability to stay on top of events, either before or as they unfold, and to exploit the opportunities offered by progressive trade liberalisation still appears to be limited in scope. Yet it is only fair to note that growers in Europe at least must contend with and are conditioned by the agricultural policy of the EU and other countries, the current state of their infrastructures, type of production system and management, available sources of capital, and the often unpredictable twists and turns of a volatile marketplace. The overall, and emerging, European pattern includes several key features.

1.1. A shift to larger, umbrella-like grower associations to gain firmer control of supply, improve bargaining power and enhance market access potential. In other words, the supply side of the equation shows increased cultivar planning, targeted investments, standardised production and greater attention to consumer demands.

1.2. A corresponding policy shift to integrate more fully the orchard-to-table pipeline. This means greater attention to guidelines and regulatory controls covering all the necessary steps to ensure that the marketed fruit is in line with target quality, packing standards and consumer expectations. One good example we see today is the Gamma 4 ready-to-eat sliced fruit or snack packs that are steadily gaining favour with consumers.

1.3. Coordinating production systems via stricter guidelines and protocols in response to market demand and to the qualityprotectionist hurdles between trading partners both outside and within the EU free-trade zone.

1.4. Product promotion via two, increasingly interconnected strategies involving supply and quality control. The first regards the commercial labels and logos growers are adopting to advertise quality and lock in consumer preference, which range from those for production system and the produce itself to those for district of origin and typical fruit character. Perhaps the most familiar of these labelling types are those for integrated fruit production (IFP) and organic production (OFP), the former being attested to by in-house or self-certification and the latter requiring obligatory outside certification under EU legislation. In fact, the EU awards to consortia from a given, identifiable district having uniform produce of even a certain range of cultivars special labels like IGP (protected geographic indication), DOP (denomination of protected origin) and DOC (denomination of controlled origin).

The second involves public agencies charged with quality controls and drafting regulations to safeguard consumers. Indeed, these norms must be adhered to by growers and wholesalers regardless of the in-house labels adopted by associations or individual holdings. Indeed, the EU has enacted a series of detailed measures on produce origin and denomination denoting the specific quality categories on packaging and most recently traceability information so that provenance, production system, post-harvest storage, distribution and market destination can be traced at a glance. All this is in addition to the norms requiring produce to be sold under a given threshold of chemical residue (MAR, maximum admissible residue) with fines for non-compliance. Yet, except in a few individual cases of in-house labelling, there is still no EU legislation covering information on quality-flavour traits like state of ripening, soluble solids and acidity content, and home storage handling for best ripening.

1.5. The last few years have also seen a series of certification regimes drafted by local government agencies at the request of the large supermarket chains and multi-national corporations to meet specific market targets like baby foods and internationally traded fresh-market produce. These enterprises account for a market share ranging from a minimum of $40 \%$ in Italy to a peak of $80 \%$ and higher in northern Europe. About a dozen of these big chains control approximately $70 \%$ of the produce market and, hence, have greater power to influence marketing standards and prices than do the large, official EU umbrella grower associations. Indeed, the big chains at times impose even stricter protocols on crop management regimes than those called for in established grower guidelines, despite the fact that the latter fully comply with current legislation (for example, threshold MAR values are lower for the chains than those set by the EU), and often request international certification attesting to their compliance with sound ecological, organizational, management, social (workers' entitlements) and other practises.

The problem with all this is that there are a number of certifying agencies and each big chain recognises only their own qualifications. For example, EUREPGAP certifies that a given fruit grower employs "good sustainable crop management measures" and the BRC that the produce has been handled under optimum conditions to ensure quality. This situation is further complicated by the fact that, for instance, the latter is accepted only by the big UK chains whereas the French and German chains want IFS certification. Thus, the agency and certification change depending on country and the big chains operating therein. The upshot is that

\footnotetext{
'Opening lecture at XIX Congresso Brasileiro de Fruticultura, "Frutas do Brasil: saúde para o mundo", Cabo Frio, Rio de Janeiro, september 17/22, 2006.

2 Dipartimento di Colture Arboree, Università di Bologna - viale Fanin 46 - 40127 Bologna
} 
if a producer group wants to broaden the range of target markets, which would include additional supermarket chains and EU countries as well as species and product quality, it must apply for any number of certifications that are not only costly per se and bureaucratically time-consuming but increase costs well beyond the value added a given market will recognize and the certifying procedures themselves are intended to secure.

1.6. Another important factor is policy and the legislation enacting it in the individual EU member-states. The key measures regarding the fruit industry fall under the rubric of the Common Market Organisation (CMO), and their translation into operational protocols falls to the EU's official grower associations (GAs). Once the protocols are approved, subsidies and financial instruments are then granted to cover market adjustment, farm restructuring (including crop conversion and varietals upgrading), extension service networks, produce marketing and promotional campaigns. The funding cap is $4 \%$ of yearly marketable produce per GA, or a maximum of $\bullet 180,000$, an amount that today is considered too low. While the overall policy goal was to further develop grower cooperatives and consortia, only in part have these objectives been met since its implementation in 1996. For example, in Italy a mere 35$40 \%$ of fruit production stems from GAs and does not on average exceed $60 \%$ in other EU countries. A significant number of growers thus have decided to remain independent of the CMO system and its benefits and run the attendant market risks. At the same time, however, the GA umbrella groups were unable to avert or remedy the severe market downturns in 2004 and 2005, with surplus supply (e.g. peach and apple) engendering a fall of farmgate returns below production costs.

1.7. Supply lines and international trade. Statistics over the last three decades clearly show a notable asymmetry among the world's major fruit-growing areas. While Europe and North and South America have enjoyed a certain upswing that has since levelled off, countries in Asia like China have seen orchard acreage soar at a sustained 5-10\% yearly. This dichotomy between East and West is to a certain extent explainable by the need to expand relatively low consumption in certain Asian and east European countries. Yet, if we also realise that in Europe's more advanced economies consumer demand for fruit over the last 4-5 years, though still relatively high, is falling, it becomes evident that global supply flows are affected and vulnerable to adverse market volatility. Indeed, the problems of the last 4-5 years can also be laid to the export pressures being exerted by the more than 60 countries producing at costs generally far lower than in Europe in increasingly successful pursuit of greater share of the latter's markets.

Yet this picture is somewhat different for producers in the southern hemisphere. These countries mainly export fresh apple, pear, grape and tropical species to Europe in the winter-spring period when Europe's own supplies are basically exhausted. So here we are dealing with a complementary exchange. Indeed, this supply pattern has generated a number of joint import-export ventures to ensure that quality controls are the same as internal ones and to justify in the face of protests by domestic growers on both sides of the divide this year-round trade.

\section{Dualism of integrated (IFP) and organic fruit (OFP) production systems}

There is no doubt that the key to interpreting development of the fruit industry is the technological shift from a yield model to a system focused more on crop quality and conservation of natural resources. Whence the term sustainable, eco-compatible production for IFP and OFP systems. While the former has in the last 15 years gained upwards of $80 \%$ of market share in apple, pear and kiwifruit in certain EU countries, it has remained at less than $50 \%$ for stonefruit, especially peach and nectarine. OFP on the other hand, given the notable and unavoidable risks inherent with the often uncertain outcome of biocontrol schemes of pest and disease and, despite increasing interest, market predictability, does not as a rule exceed $1-2 \%$ of all output, though there are peaks of over $5 \%$ in Switzerland, Germany and Denmark. The OFP acreage figures reported by a 2004 Europe-wide survey are likely over-estimated since they are linked to EU subsidies that have since been phased out.

While IFP thus corresponds to an inevitable market necessity and should soon cover almost all output, OFP relies on perceived greater health safety because of the almost complete absence of residues and the favourable perception of consumers, especially younger ones, who are convinced that buying organic produce is beneficial to the environment and are willing to pay the premium. Note in this connection, however, that while that premium was 30$40 \%$ higher than the standard price for a few years, it has since dropped to $10-30 \%$ and, in cases of lower quality produce, to nil, the same pattern seen before with IFP even for the best quality produce.

Like research carried out in other EU countries on various crops, University of Bologna studies over the past 5 years on apple and peach show that yields of OFP fruits are consistently 20-30\% lower than IFP's (Sansavini, 2002). This gap is in part due to a higher incidence of pathogens and pests, which are not easily checked by authorised control measures, and in part to lower tree cropping capacity, a problem probably linked to nutritional and soil factors. For example, while nitrogen input is restricted in IFP, being metered out via fertigation scheduling, in OFP $\mathrm{N}$ is released gradually throughout the year, even at times when not needed, via the process of nitrification. To obviate these problems, OFP should be practised uniformly (not mixed with conventional crops) over large expanses of acreage in climatically conducive, low-humidity districts to prevent pathogens reaching critical mass and to promote the development and control power of beneficial organisms.

Yet it should also be noted that biocontrol has registered important successes in the last few years. One example is the use of sex pheromone traps, which have been widely employed to control Carpocapsa pomonella, codling moth, in highland apple districts (though chemical treatments are needed with it in lowland districts). Other limited, or experimental, success stories include the use of various biocides like bacteria and viruses and augur well for the future, although it is still unclear whether the agents authorised for use can be developed or not via biotechnology techniques. Given too the inefficiency of various plant-based pesticides and biocides, OFP is still considered an outpost of IFP. Thus, only when a biocontrol technique can ensure that efficiency, will it be phased into IFP, even if costs are high, and translate into a benefit for consumers. Unfortunately, OFP is still too riddled with ideologies and should rely more on science than on faith in principles to secure subsidies and privileges not accorded to IFP, which after all is not wishful thinking but a mass-market reality.

Plant protection is thus an open-ended and passionate field of research that every year comes up with innovations for both IFP and OFP, including increasingly refined approaches to monitoring the biological cycles of pathogens, pests and beneficial. These advances have become indispensable not only to researchers but also to extension officers and even to growers, who can appropriately schedule and apply these products on their own. This is why IFP has achieved such high levels of safety for both producer and consumer.

Research of course covers many fields and not just plant protection. Indeed, a panel of experts in many fields is what is needed as a catalyst to synthesise our knowledge and draft appropriate guidelines for field application by growers and extension services to optimise crop management regimes. This is the case of IFP, for 
example, whose initial protocols were developed 20 years ago in Italy, the Netherlands and Switzerland from the experience derived in the 1970s and early 1980s. As experience and expertise have deepened over the last decade, guidelines now vary from country to country, region to region and even from one GA to another in the same area. This because there is still no unifying EU directive, which is now a commercial necessity.

While the IOBC (OILB), the EU biocontrol board, attempted to use its expertise and draft applicable guidelines in a range of circumstances for growers and GAs who wanted to use the IFP label even for commercial purposes, there are still too few GAs that follow this orthodox approach (see Annex 1). So, an EU regulatory directive, based on the official one used for years by OFP, is once again on the agenda. Indeed, the fact that growers and GAs are at liberty to do as they wish in this connection (based on in-house certification like that for the IFP Agros project in Bolzano) can lead to confusion in the marketplace. One good example is the controversy over admissible treatment chemicals and their residues. While the MAR thresholds are well-established by the EU for interunion trading, they differ from and within each country and are hard to compare parametrically. This is why GAs has not only argued for uniform MAR levels but even for a regulatory policy to put the IFP house in order. An EU draft proposal has been worked up (Annexes $2 \& 3$, in Spanish) and will soon be submitted for examination. One thorny issue is that, despite assurances on free trade, each country will want a clause to safeguard its exports and impose a "miniphytosanitary-barrier' for imports.

Non-European countries also have a stake in these new regulations, if and when they are approved, so their exports will not be at risk. Indeed, there have been cases in which South American produce has been barred from entry because fruit residues did not comply with those set by an individual EU country.

\section{Research Compass}

There have never been technical advances in the industry that are not the fruit of targeted research. Apart from crop protection, the main focal points of research today include:

- Genetics and breeding for novel cultivars better suited to markets, hardier and more resistant to biotic and abiotic stresses

- Soil management, nutrition and fertilizers, water supply, irrigation and fertigation, drought and salinity

- Orchard management, high density planting (HDP), rootstocks, training systems, pruning and thinning

- Rooting, propagation, in vitro culture, nursery technology

- Environmental physiology

- Use of growth regulators; yield efficiency

- Monitoring and modelling systems for plant phenological and physical status

- Destructive and non-destructive analysis for fruit quality; sensory tests, standardized methodologies

- Post-harvest technology, physiological disorders and rots, storage technology, shelf-life control

- New technologies in packaging, logistics, services, electronic controls

- Enhancement of mechanisation systems and mechanical aids

- Economic studies and cost/benefit analysis, market perspectives and trends

Clearly, these interests no longer fall under textbook pomology or traditional arboriculture as in the past, but belong to identifiable scientific matrices applied to the fruit industry like biology/physiology, engineering, biochemistry, genetics and biotechnology. Such a range of expertise thus calls for interdisciplinary projects managed by an authoritative project head or lead scientist to establish collaborations, identify synergies, prevent overlaps, supervise flow charts, assess impacts, and decide dissemination forums and application of results (development). This is the key to the successful securing of funding and accountability.

\subsection{European Research Projects}

One of the major benefits of belonging to a community of 25 countries with 480 million inhabitants is the potential of putting together international research projects to pursue common goals in a framework of synergies and complementary partnerships. It is no secret that the EU and its member-states have for some time been reevaluating the public funding of research in agriculture, including the fruit industry. Individual governments have in fact devolved the responsibility for applied research to regional authorities under EU oversight and handed the task of basic and core research to universities and key national networks, encouraging at the same time the involvement of private industry and growers (which now account in some countries for up to $50 \%$ of financing for applied projects). The overall funds allocated by each member-state to the EU pool are on the rise, though not yet to the same extent as in the US, Canada and Japan, and then reapportioned through the socalled 'frame programmes', which are thus becoming increasingly important for each member-state. Italy, for example, received a budget of $8-10 \%$ of EU allocations in the current sixth frame programme (2002-2007), almost double some of its past budgets. The next fiveyear programme is scheduled to start in 2007 and will have an overall budget of $\bullet 54$ billion for all research sectors, a sizeable increase over the current figure.

Projects submitted for EU funding must meet certain requisites.

-Topics must be in line with those set forth in the frame programme - Targets, objectives and deliverables must be scientifically significant and supported by operational facilities of proven efficiency and reliability

-Each project leader must be a recognised authority in the international scientific community

-Engagement with partners capable of research input and of employing project results and technological deliverables

- Organising a broad-based international research network capable of supplying other resources

-Deliverables must have demonstrable impact on rural development, especially in marginal areas, generate income, and be of socioeconomic and ecological benefit.

To grasp just how important the EU approach to collegial research has become, let us take a look at three topical examples in the fruit industry.

\subsection{ISAFRUIT}

This is an integrated project that runs from 2006 to 2010 and involves about sixty research centres from all European countries with a fruit industry.

\section{ISAFRUIT-UE INTEGRATED PROJECT (2006-2010)}

(61 partners, 40 institutes, 21 EU members)

\section{Mission}

- improve human health \& increase fruit

consumption

Strategic objectives

- sustainable fruit production

- fruit pipeline; remove barriers:

a) insufficient quality \& safety

b) limited availability of certain fruits

c) lack of sufficient consumer education

d) high prices of fruits $\&$ derivatives

Built on 8 pillars:

1) Consumer demand $\&$ responsive market chain 
2) Fruit \& human health;

3) Improve appeal \& nutritional value of processed fruit

4) Quality, safety and sustainability

5) Improve pre- \& postharvest chain management

6) Genetics of fruit quality \& implementation of better cultivars

7) Dissemination \& transfer of knowledge

8) Project management \& integration

Overall budget for 54-month project (ME)

\begin{tabular}{lccccc}
\hline & $\begin{array}{l}\text { RTD/mov } \\
(\mathrm{M} €)\end{array}$ & $\begin{array}{c}\text { Demonstrative } \\
\text { activities }\end{array}$ & Training & Consortium & Total \\
\cline { 1 - 5 } Eligible costs & 19.832 & 0.122 & 0.419 & 0.966 & 21.440 \\
\hline EC & 12.335 & 0.007 & 0.419 & 0.966 & 13.798 \\
contribution & & & & & \\
\hline
\end{tabular}

\subsection{UE Platform "Food for life" (2007 - 2012)}

Two-year joint planning of the big food companies, the agriculture sector and scientific institutions.

Aims: define research, technology and novel deliverables in:

- Foods \& consumer health

- Product quality \& preparation

- Sustainability of production systems

- Food safety

- Food pipeline management

- Communication, training \& know-how transfer.

Main focus: process physiology, quality analyses, fruit composition, neutraceutics, health components, chemical-medical validation, microbiology \& processing technology.

\subsection{UE Platform "Plants for the future" (2007 - 2012) Main aims:}

- a) breeding \& biotechnology to create future plants (more stress resistant/tolerant, energy efficient

- b) high-quality fruit; nutritional \& therapeutic (neutraceutics) value Research agenda

1) Public health \& food safety (consumer customised)

2) Optimise agritechnology for sustainability; promote biodiversity, enhance rural landscapes

3) Development of pharmaceutical products, plants for energy, crop processing in biofactories

4) Competitiveness, consumer choice \& governance, human resources.

\section{Key technical advances in the fruit industry}

It should be underscored that the industry's big technological leap over the last half-century has involved at least four main, equally important factors, although driven by their own engines, different and chronologically separate models.

- The first is genetics and breeding, whose contributions have had more to do with different fruit traits and quality properties in response to market demand than to per-acre orchard yield (hard to increase further)

- The second is upgraded crop management practises ranging from soil to ground-based tree governance regimes, innovations made possible by advances in biology, chemistry, soil and plant physiology, the use of information technology (IP) in orchard management, detection devices and dissemination and communication

- The next is the integration and optimisation of the former two factors in working out the principles and protocols of IFP and OFP systems

- The last is mechanization, a field that reached its peak in the latter part of the 20th century for crop management and protection practises, and, although picking and pruning are not fully mechanized, they use equipment like self-propelled platforms, hydraulic shears and so on that have cut labour outlays from 3$600 \mathrm{~h} / \mathrm{ha}$ in the $1950 \mathrm{~s}$ to about $100 \mathrm{~h} / \mathrm{ha}$ or less today (compared with 5-10 days/ha needed for field crops).

Let us now look at new developments and the factors generating them.

\subsection{New orchard design and management practises}

Almost all orchard species throughout the EU today are ran under modern management systems enabling progressively higher density plantings (HDPs) via a combination of factors like appropriately dwarfing stocks for altered tree habit, training systems and pruning regimes. These designs all follow differing, technically viable models largely aimed at delivering greater yield efficiency and fruit quality, with economic factor deciding which regime to pursue district-by-district, species by species. The range of options is broad and densities alone can go from an average 1,000 to 4,000 trees/ha for apple, 2-5,000 for pear and 500-1,500 for peach depending on the stock, cultivar and training system best suited to each model. For example, the various M9 stock clones in apple can reduce vigour by $60-70 \%$ vis à vis more vigorous ones like M111, while the reduction in peach is $20-30 \%$ and in pear on quince $50-90 \%$ vis à vis seedling stock..

Important too are the changes in training systems, which are backed up by numerous experimental data to guide growers in decision-making, as well as those in pruning regimes, which are often accompanied by fruit thinning. All of these measures are aimed not so much at enhancing yield as upgrading crop quality, which as in peach often requires costly measures so as to prevent high discard rates at harvest. The European countries with the most advanced pre-harvest management regimes and related extension services are France, Italy, Poland, the Netherlands, Spain and Switzerland (see references).

\subsection{Soil, water, nutrient \& tree management}

Soil management operations like grassing, tilling, weeding, dressing, irrigation and fertigation are undergoing thorough revamping to upgrade practical application. These changes encompass much more than sward and under-row chemical weeding rather than tilling. Indeed, grassing itself has varied following new insights into nutrient uptake, translocation and storage, and the interaction of rhizosphere-tree habit-soil (Neilsen et al., 2002). Current findings have also focused on the soil's physical and microbiological status induced by management measures and its nutrient status during the times of the year when the tree most needs them. Great strides have also been made in orchard design, especially in HDP layouts and their upper limits, stocks, training systems, pruning, fruit thinning, use of bioregulators (Costa and Ramina, 2005; Sansavini, 2002, 2003). Let us now look at the key advances in soil management.

a) Upgraded weeding and/or mulching practises as per IFP protocols that are best suited to element combinations of low competitiveness or having allelopathic or auxiliary biological properties, the siderophore- $\mathrm{N}$-fixing interaction being one example.

b) Novel approaches in determining macro- and micronutrient demands, their delivery and efficiency and in limiting their run-off to water tables and leaching. quality.

c) Notable savings of all energy inputs while enhancing

One of the most important examples of these advances is the reduction in $\mathrm{N}$-use via targeted scheduling and metering rates with time-lapse formulas. Indeed, $\mathrm{N}$ inputs have been reduced in apple and pear by two-thirds, dropping from 150-180 units/ha to just 40-70 and in peach by almost half, going from 200-250 units/ha to $120-150$. 
While much is now known about indirect $\mathrm{N}$ supplies and its budget, $\mathrm{N}$ flow is notably complicated and careful monitoring is necessary to prevent under- and over-supply (Grassi et al., 2002; Tagliavini and Rombolà, 2001, Tagliavini et al., 1998).

Iron uptake and metabolism and various forms of related chlorosis have also been investigated under many EU projects, including original contributions by the DCA. These studies suggest that we may be approaching a solution to chlorosis problems in sub-lime soils that mainly affect peach, kiwifruit, pear and grapevine (Rombola and Tagliavini, in press).

Another advance that is being widely applied focuses on plant water potential and budget calculated via evapotranspiration and crop coefficients to schedule daily and weekly inputs. This approach makes it possible to save water and to take biological advantage of water stress at times of peak seasonal tree growth, a method called controlled water deficit that has been successfully applied in pear and apple but more difficult to use with peach (P. Mannini, 2004).

Organic dressings in OFP orchards are also under study. Much work still needs to be done and it must include the allelopathic effects of individual grasses on and the role played by many mineralorganic compounds, which in excess application can induce adverse effects, in plant functions and their consequences in relation to dressing. Other examples include the fact that repeated interrow tilling over the years reduces plant biomass more than grassing (Giovannini et al., 2001) and that interring Brassicacae like Eruca sativa, cv Nemal, and Raphanus sativu,cv Boss, has a biocide effect on nematodes (Meloidogyne spp., Heterodera spp), as experimentally reported by Dr. G. Curto of the Emilia-Romagna Region's Phytosanitary Service.

\subsection{Mechanization and precision technology}

Machinery has indeed been a significant driving force in both technically upgrading various practices and in freeing fruit growers from much of their manual work load. Yet, despite these key innovations, the manual labour pool still handles a significant share of field work and is one of the limiting factors to the spread of the fruit industry in many areas. Today orchards need up to 80-100 days/ha of manual labour (more than half skilled), of which picking accounts for $40 \%$ and more, although mechanical harvesting is widely practiced for olive, walnut, almond and other nuts as well as certain stone fruits for processing like plum, apricot, cherry (rarely cling peaches).

There have also been significant advances in postharvest handling and storage. To the electronically automated sorting, grading and packing lines are to be added the more recent ones featuring micro-chips and sensors for selecting individual fruits in relation to ripening stage and quality (like NIR-laser techniques) and not simply as to colour and size. All of these innovations are based on IT approaches and are the forerunners of what will become a digital revolution in horticulture in general and not just in postharvest strategies.

\subsection{Chemistry and sustainable technology}

The intensive fruit industry is a fundamental part of last century's "green revolution", but it is inappropriate to identify the concepts of intensivity with the over-exploitation of natural resources like soil impoverishment and excessive energy inputs. Today we seem to be moving away from the epoch of waste towards one of savings, although this trend has been reversed by the concept of integrated pest management (IPM), a cornerstone of the modern fruit industry, whose principles have been embraced by the philosophy of sustainable farming and rural development. Indeed, integrated crop production has become the hallmark of planning, technical efficiency and environmental stewardship while ensuring equitable returns for growers. All the management practices developed in the last 10-15 years have thus been radically overhauled, with yearly updates in IPM and IFP from targeted research and experimentation. One formidable result of all this has been the pronounced reduction in the amount of synthetic chemical inputs and the consequent rise in organic, organo-mineral and compost dressings per unit of orchard acreage.

The amount of chemical pesticides (most of low anthropic toxicity) has indeed dropped to less than $40-50 \mathrm{~kg} / \mathrm{ha}$, and active ingredients of increasingly lower amounts and selectivity are fast coming into use. While one exception to this trend is OFP, whose protocols call for the use of such traditional agents as copper salt and lime sulphur, so that overall inputs can climb to more than 100 $\mathrm{kg} / \mathrm{ha}$. There is, however, the example of sex-attractant pheromones, probably the most significant innovation in pest control over the last decade and an especially powerful tool in apple.

Another new pest-control tool that is beginning to spread is biocontrol via the use of such biocides as against viruses, bacteria and fungi (from Trichoderma), although further experimental tests are still needed. It is thus possible that over the next few years biocontrol will become more widespread at the expense of chemical methods. Indeed, IFP will in all likelihood increasingly resort to the use of biocontrol, extracts, natural and synthetic compounds, thereby moving closer to organic approaches, though not at the expense of overall results and economic returns.

Plant and soil nutrition too has changed. Greater insights into the nitrogen and carbon cycles and into the uptake, transport and metabolisation of both macro- and micro-nutrients have led to major changes in input planning and scheduling (Tagliavini and Rombolà, 2001; Tagliavini and Marangoni, 2002). These new approaches are designed to limit nutrient inputs by achieving both an optimum tree energy budget and control over it so as to regulate the partitioning of carbohydrates and metabolites for fruiting and yield quality by constraining excessive energy uptake by limbs, leaves, trunk and roots. Indeed, a number of field tests have shown that $\mathrm{N}$ rates of only $40-70 \mathrm{~kg} / \mathrm{ha}$ are enough for apple and pear and $70-120$ for peach. This compared to the up to $200-250 \mathrm{~kg} / \mathrm{ha} \mathrm{N}$ employed thirty years ago, largely as nitrate and just as largely ending up as aquifer-polluting run-off.

Significant advances have also been registered in crop physiology. These studies into the processes of nutrient uptake, transport and metabolism by the various plant organs can mostly be attributed not only to greater insights provided by biochemistry and soil chemistry but also to IT-based portable systems with infrared analysers enabling field monitoring of leaves and with ADC and CIRAS data loggers to measure whole-canopy photosynthesis and transpiration directly or to derive photosynthesis data indirectly via fluorescence (Corelli Grappadelli, op. cit.). For example, the biosynthetic pathways of ethylene (Fig. 3) and of gibberellins (Fig. 4) are now well known and have laid the groundwork for studies, including those at the molecular level, of the compounds that accelerate by-pass or block enzyme functions involved in fruit ripening and shoot growth. These insights have made possible the chemical synthesis of many substances designed to alter normal processes. One good case in point includes blocking ethylene biosynthesis and release in order to increase fruit shelf-life. There is also much work today involving the use of molecules like MCP to control ripening by extending the on-tree life of fruit and, in the attempt, enhance its quality. Other examples include growth retardants, although not yet or no longer authorized for commercial use except for a few exceptions, which are usually anti-gibberellic in nature as they interrupt gibberellin's biosynthesis, like Cultarpaclobutrazol (Fig. 4).

Yet it would be a mistake to think that the advances in applied biochemistry all belong to the post-WWII period. Lest we forget, J. Liebig (1802-1873) was the first to show that the carbon in plants comes from the air and not soil humus, although he also held that 
most $\mathrm{N}$ was taken up by the atmosphere since bacteria $\mathrm{N}$-fixing had not yet been discovered. Thus, in the decades before the turn of the $20^{\text {th }}$ century, agricultural science was largely linked to agro-chemistry and to the goals of employing $\mathrm{N}$ and other elements to upgrade soil fertility and increase crop yields. These empirical ideas and the management approaches they engendered, which held sway for many years, were finally overturned in the 1960s-1970s first by economists via the theory of 'marginal use' and then by biologists and agronomists, who showed the adverse effects of the indiscriminate use of fertilizers, potassium dressing in Germany being but one such example. Indeed, the new research-based findings largely laid the groundwork for the protocols of IFP and the idea of sustainability, their main thrust being to limit the soil run-off of all energy inputs, whence the concept of localised fertigation, and to upgrade the plant growth-to-crop quality ratio. Other soil management techniques that exemplify this new technical orientation, like grass sward along with under-row weeding, are all designed to conserve soil energy by enhancing soil structure and fertility (Figs. 5, 6, 7).

Note that most of the routinely used growth regulators, like auxines, gibberellins, cytokinins and ethylene, and all the synthetic ones which have been used for years have been banned, while others like GA 3 and GA 4+7 are routinely used, even in the nursery industry. While new molecules are under study, it will take years to secure authorisation. Note too that certain growth regulators have historically played an important role in physiology studies, as for example in fruiting, rhizogenesis, cell-differentiation and ripening. Nor is this role at an end. One example is the recent commercial authorisation of prohexadione-Ca (Regalis, BASF), which both exerts a notable retardant effect (as shown in pear and apple) and regulates or limits shoot susceptibility to fireblight and certain fungi diseases. Indeed, ongoing studies indicate its ability to alter the metabolic pathways of phenols like catechins, flavonoids and others, which appear to boost plant resistance to pathogens (Gosch et al., 2003; Stich et al., 2002). Today Regalis is the only bioregulator approved for use in Italy, although the induced control it exerts is notably inferior to Cultar's.

There is too a broad-ranging family of bioregulators that have a marked anti-fungus action, especially in regard to mildew (e.g. Bayleton, a triazolic compound like paclobutrazol), or have proven to be strong weed killers, though these are not as a rule used in the fruit industry (auxines like 2,4D). The insights being gained through studies in molecular biology are exponentially boosting our scientific understanding from year to year. These advances may well lead to new tree-growth and, especially, fruiting-control techniques, innovations that would be very welcome in peach given its need for time-consuming fruit thinning and the fact that it is practically insensitive to chemical thinning agents. A number of molecules are being looked at for application during anthesis or before, a window which would also obviate toxicological risks (G. Costa et al., 2003).

\subsection{Breeding}

Despite the fact that it takes 10 to 20 years to breed new varieties, developing novel cultivars has been a top priority in Europe, especially for species with a rapid turnover rate like peach. The key objectives of programmes everywhere include introgressing diseaseresistance genes in novel genotypes, upgrading fruit quality, storability and shelf-life, and extending early and late seasonality. Indeed, seasonal de-coupling in southern districts via such techniques as forcing regimes for table grape, strawberry and certain early-ripening stone fruits, along with market integration of fruit from mountain and northern districts that naturally delay ripening, has notably extended the calendar of summer fruit for consumers. Examples include the 6-7 months that peaches are now found on the market, the 2-3 months for cherry, the 8-10 months for strawberry and the 3-4 months for small berries. In other words, summer fruits now have a greater marketing span thanks to a combination of genetic, environmental and management factors. If we add to this the as yet unexpressed potential of genetics, it should not take long to see another big stride forward. Of the many traits geneticists are working on, molecular control of their expression via the identification of markers for selecting parental lines and then in early MAS for breeding probably tops the list since it will greatly speed up breeding time.

There have also been advances in quality diversification of notable market importance. Examples include the spread of new yellow-flesh cultivars of Actinidia chinensis like cvs. Jintao and the late-ripening Zespri ${ }^{\mathrm{TM}}$ Gold, with a 3-4-week longer growing season, and new varieties of Actinidia deliciosa that are alternatives to the female Hayward like Summer Kiwi ${ }^{\mathrm{TM}}$ (3373 and 4605) that extend the early-season autumn calendar by more than a month. In this connection there are also novel self-fertile varieties of sweet cherry from Canadian and Italian programmes like Sweet Heart and Grace Star and Black Star, new apricots like the early Aurora that ripens in late May-early June in northern districts and late ripeness of North American and French origin. Indeed, there is already a broad range of large, very appealing and tasty late cultivars that have extended marketing to mid-August—an unthinkable goal just a few years ago. And, though apricot has always been yellow, genotypes featuring bright red, large-sized fruit are becoming popular and even apparently being mistaken for peach.

Perhaps, however, the most spectacular novelties have come in peach, a sector that has seen over the last 20 years the release of numerous and attractive nectarines that are hardly distinguishable one from the other in coloration, like the $100 \%$ bright red Big Top, Zaigher series and Bradford, but each with a distinct flavour, ranging from tart, sub-acid, peach-like and honey-like, and flesh texture. Some of these also withstand handling better than peach while others are susceptible to physiological disorders in storage or to rot from Monilia and other fungi in field and in post-harvest. There are bound to be surprises in the near future where novel varieties are concerned as new traits like stony-hard, red, ice, non-anthocyanin flesh and flat, Chinese-like shapes are about to come on-line (Sansavini et al., 2006). While nectarines have enjoyed a notable commercial success in northern areas, even to the point of supplanting peaches, the peach/nectarine coupling is bound to last for reasons of market differentiation.

Pear is another key industry sector. The focus of breeding here, however, is not so much to develop new cultivars of better quality than the old ones, some of which are unsurpassable, as to introduce novel traits like resistance to fireblight and psylla for trees and red-skin for fruit (Bellini et al., 2000; Musacchi et al., 2006).

Apple too has seen advances, especially with GM plants. The first was at East Malling in the UK with Greensleeves, a cultivar developed with the antisense ethylene-inhibiting precursor for longer shelf-life. Next came gene transformation on the Continent via Agrobacterium tumefaciens, including the work done at Bologna's DCA to modify cv. Gala so it became resistant to scab (Venturia inaequalis) by introgressing the HcrVf2 gene, which was taken from an ornamental apple and has a sequence homologous to that carrying resistance to Cladosporium fulvum in tomato (Belfanti et al., 2004). The $V f$-transformed apple plants still await field testing and other checks and, like many other such projects in Italy and Europe, are on hold at the moment.

Genetics has also disclosed the biological basis of S-locuscontrolled sterility in pome and stone-fruit species. The mutated genes for gametophytic incompatibility of this locus have been identified and transferred to breed self-fertile cherry cultivars. Today, given the success of self-fertile almond (largely due to Italian germplasm), studies are focusing on allele segregation in pear, with the goal of self-compatibility looming on the horizon (Tassinari et al., 2001) 


\section{New apple and fruit releases: propagation rights extended to the entire pipeline?}

About $80 \%$ of apple nursery supply is made up of 'mutants' that are merely clones legally renamed as cultivars. Some of them are unstable chimeras in which certain traits are subject to regression and such undesirable ones as low-yielding trees and fruit of diminished storability or quality may emerge. But even the clones featuring improved traits like spur habit and distinctive coloration also carry the risk of regression. It is these new coloured mutants that nurserymen use as marketing spearheads. Yet, if these 'varieties' cannot be distinguished by phenotype, whether it be fruit, growth habit or other typifying tree traits, (molecular fingerprinting seems to be able to detect the genetic factors via transposon technology so as to discriminate the various clones), the sheer number of clones of a given variety can lead to confusion among growers (a good case in point being cv. Gala).

So breeders now have to safeguard their 'novelties' throughout the pipeline. This means they essentially have control over, and enjoy the royalties on, plant propagation; orchard plantings and even the yield growers end up with. Like nurserymen, growers have become simple product suppliers while taking on the unknowns, costs and risks an orchard entails right from initial planting but without adequate guarantees in terms of farmgate or a share in the added value that such 'protection' should entitle them to. This is the issue that has come to the fore since the mid-1990s, when a number of club-like alliances resembling small multi-national corporations and made up of associated breeders, nurseries and marketers began to dot the landscape. It is to be hoped that grower associations will join forces with these groups so as to make their voice heard from within.

While by now everyone knows the alliance that controls cv. Pink Lady ${ }^{\circledR}$ and Cripps Pink* and how long it took to get it organised, at least five more such international alliances (the French being the consolidated leaders in Europe) have cropped up: Tentation Delblush* (France), Cameo ${ }^{\circledR}$ Caudel and Honeycrisp ${ }^{\circledR}$ Minn. 1711R (US), Pacific Rose ${ }^{\circledR}$, Scires* and Scired* (New Zealand), Robbos $^{\circledR}$, Elise* and Santana* (the Netherlands), Rubens ${ }^{\circledR}$ and Civni* (Italy), and others are on the way.

One of the main advantages, and surely a plus, is supposed to be apple supply scheduling, both in nursery and orchard, by establishing a priori growing districts, plantation acreage, yields and market throughput. Proponents hope to regulate supply after inducing consumer demand and expectations through marketing campaigns. This strategy is designed to assure higher returns on the already high investments alliance members-breeders, nurserymen, growers, marketers, quality-control units-have to make, the upshot being an exclusive pipeline controlled by the alliance holding the proprietary rights.

\subsection{In vitro culture and micropropagation}

The rise in the application importance of cell and tissue culture has served as models for the study of a range of phenomena like rhizogenesis, cell-differentiation, callus growth, somatic variation and embryogenesis. A number of micropropagation techniques have been developed from basic research starting from strawberry and on to rootstock clones and fruit variation.

While strawberry was eventually excluded from micropropagation protocols because of the alarming results from field tests (degenerative epigenetic forms, morphological variations, pheno-somatic off-colouring), micropropagation continued for mother trees and their virus-indexing in pre-multiplication (superelite). It took a decade of field testing to ascertain tree performance and investigate such epigenetic phenomena as thorniness and other juvenility symptoms.

Research laboratories, which no longer work on routine techniques, are now focused on new approaches to mass propagation that have potential interest for the nursery industry, bioreactors in liquid media being one example, and on the effectiveness of sub-cultures, auto- and hetero-tropism, in vitro propagation of recalcitrant forest species like ash and chestnut, somatic tissue regeneration, cell competence for transformation, and physiological variables. Indeed, much of this work is also aimed at eventual genetic transformation. In-vitro culture is still very much used in modelling various phenomena like scion-stock graft incompatibility and stock cell apoptosis (Crescimanno et al., 1999).

\subsection{Biotechnology \& GM plants}

Public opinion often seems to labour under the mistaken idea that biotechnology simply means manipulating DNA (whence the term genetic engineering proper) to develop 'modified' plants carrying novel traits, i.e. artificially introgressed genes from other plants or even genetically remote organisms like viruses and bacteria. Yet this is only the most publicised part of biotechnology. Indeed, molecular biology and all the tools it has generated to analyse DNA and genomes are essential to studying genetics, physiology and other bio-processes ranging from plant fertility to the morphogenesis of various organs, including fruit. According to Maggiore and Salamini, the very basis of agronomy should be revisited and updated in the light of the new insights afforded by molecular biology. These biotech innovations are becoming a signal aid in traditional breeding and propagation. Table 6 summarises key potential areas of non-GMO biotech approaches and, hence, do not elicit objections and criticism. Indeed, these tools will prove useful in achieving the goals the fruit industry will pursue over the next few years like selecting parents carrying traits not disclosed in the phenotype, early selection of seedlings from crosses, identifying functional genes (the genome of a species may have several thousand genes like grapevine's approximately 50,000) that control morph-functional traits and metabolic processes like fruit ripening, flesh softening, flavour and those involved in cultivation, protection and cropping.

As is well known, GMO technology has been banned in Italy and, with numerous reservations, even in research for the last ten years. Italy has thus lost the chance to develop, test and produce GM plants for the future of its agriculture, thereby leaving the field in the hands of multinationals that today control the market for GM maize, soybean and rape seeds. Even the EU itself has, with few exceptions, not only impeded GM plant cultivation through a series of moratoria and bans (e.g. its precautionary principle and labelling policy), though France and Germany have supported GM research, but also limited imports of GM-derived products for human and animal nutrition. As a matter of fact, several member-states, including Italy, have recently decided not to comply with the policy of coexistence established by the EU to allow the cultivation of GM plants with conventional ones under a safe-distance principle. While even the experts are arguing over this issue, no fewer than 12 regional governments in Italy have declared themselves 'GM-free' zones, leaving the EU to deal with the problem in a future directive.

It is obvious that fruit species, and especially research, have been adversely affected by all this political wrangling in that no GM fruit cultivar has yet been marketed except papaya and banana. While a number of GM plants of most species have been bred in Europe, mainly for biotic resistances, they are still at the testing stage (Italy has banned even this) and it will be years before any reach European markets (Mezzetti e Gentile, 2005). The two species at the most advanced stage of development today are grapevine and apple.

\subsection{Maturity, ripening, quality}

Fruit quality depends above all on its reaching full maturity, 
a process that has never seen as many studies from various angles (molecular-physiological, biochemical-physical, sensory measurements) as it has in the last few years. All this work marks a gradual reprise of the importance flavour and taste has, and had been forgotten or omitted by labelling, in the word quality. While experts in every sector complain that more could be done to enhance quality for consumers and technical limits in the system still exist, great strides have been made in post-harvest handling and sorting, storage and atmosphere, and consumer packaging. A good example of these advances is non-destructive approaches to fruit quality assays.

There are dozens, perhaps upward of a hundred, of these machines in Italy's biggest packing houses, a sector where the country has always been in the vanguard. As soon as it is known how advantageous these units are for consumers as well as the industry itself, there will be a new system of commercial fruit grading. At the moment, the industry has incurred higher costs for the introduction of NIR grading, which requires more sorting and packing lines.

Another advance in the 'non-parametric' measurement of quality is via sensory assessment of fruit traits using panel tests and comparative analytical techniques. Panel tests provide more information than gas-chromatography and can interpret and spot beforehand consumer taste preferences and market trends, thus providing a realistic fruit flavour profile (Donati et al., 2003). Another important area of novel research linked to quality is the study of food health properties and chemical-biological components by medicine, bromatology and dietetics. The most notable advances have come in phenols and anti-oxidants, compounds found in fruits ranging from small berries to apple, cherry, kiwi and so on. Researchers in Italy and Germany have already investigated polyphenols, especially in apple (Vanzani et al., 2005; Vrhovsek et al., 2004), which are part of a numerous family as the metabolic pathway shows in Fig. 24 (Feucht and Treutter, 1999). Yet little is still known about other useful compounds. The anti-oxidant molecules, for example, cover an even broader range of compounds and it will take a few years more to know how many health benefits fruit can give not only as to cultivar but also as to fruit ripening stage and provenance. Yet we can already foresee medical prescriptions for fruit tailored to age, profession and other consumer traits of individual patients. In other words, we are moving towards the consumption of functional fruit and other foods.

\section{Conclusions: fruit industry globalisation and Brazil-EU cooperation}

This overview of the research-based innovations that are driving the efforts of the fruit industry to keep ahead of the competitive curve in an export-import global marketplace has certain ramifications in enhancing closer ties between Europe and Brazil. Indeed, there is no doubt that Brazil can boost its export profile to Europe not only for orange and other tropical fruits (I think it's topranked in juice concentrates) but also for temperate fruits if it keeps in mind four priorities that Europe holds as standard procedure.

- Economic, social, environmental sustainability of production systems by promoting the growing districts that are best suited to a given crop and have the best infrastructures for rural development.

- Conservation of the environment, agro-ecosystems, energy resources (soil, rhizosphere, fertility, surface and aquifer water supplies) and, by protecting species varieties no longer cultivated biodiversity.

- Safeguard rural health through job security and public health via safe and genuine produce.

- Promote a culture of quality as to genetics, origin (growing district), and specificity and quality standards.
- Bring into line supply and markets, cultivars and marketing calendars, organise the field-to-table pipeline (including consumer packaging, logistics and services)

- Marketing promotions (including genetic novelties) and consumer education.

In other words, Brazil should take this European philosophy and its consequences on market trends into account. For example, together with price-competitive supply (given the cost differential), it must demonstrate to a wealthy European marketplace that fruit quality is recognisably certified via transparent traceability of crop and production system (IFP, OFP). Orchards must be under constant monitoring and transport logistics capable of keeping produce fresh for at least three weeks so as to enable Europe's wholesalers to distribute it to markets.

Of course, the federal government must support its fruit industry to boost

a) capital investments

b) technology innovations (Italy can contribute a lot in management techniques, machinery, information technology, plant protection and so on)

c) transport and communication networks

d) proper oversight of production, markets, crop management protocols and certification.

While these are domestic measures, Brazil can also play a leading role in international cooperation and collaboration. Indeed, the EU encourages cooperation at all levels, including R\&D (specific clauses in big projects now being drafted), research networks, exchange agreements with universities and institutes at both ends (Bologna has one for PhD students with Pelotas and collaborative arrangements with various programmes), education, professional training and even trade. The key is co-habiting with EU regulations.

One encouraging example is what EU growers are doing to boost trade with Europe itself (and the possibility of increasing exports to Brazil tomorrow). They are

1) setting up joint ventures South American partners to extend marketing seasonality in Europe by importing very early and lateripening produce as well as typical Brazilian fruits.

2) purchasing or managing large tracts of acreage for fruit crops as has been done by US firms. This will mean establishing new trademarks to ensure year-round supply

3) reorganize the sale and use in Brazil of European technology, know-how, IFP and OFP, monitoring techniques and cooperation with Brazilian firms to ensure success

4) create trade alliances of reciprocal advantage to ensure joint market profile.

\section{Abstract}

The global fruit industry has been undergoing impressive technical and organisational advances, often serving as bellwether and caution light for the entire agricultural sector. Indeed, the fruit industry first came up with the principles of intensive production systems to enhance market competitiveness, of integrated production (IFP, a logical outcome of integrated pest management, IPM,) stewardship of the environment and consumer health, and of organic farming, which is a tough test of growers' good faith and guidelines but also instils greater trust in consumers. On other words, were are now going from a yield-based model to a more virtuous one designed to enhance produce quality traits, food security to meet market demands and consumer rights, and stewardship of agroecosystems and non-renewable resources like soil and the environment.

Research has played a key role in developing novel technological advances to achieve these significant milestones, though there is still much work to do. All of this has been made 
possible whenever pomology and experimentation were free to think outside the box of traditional crop management practises and exploit and integrate novel technological advances in such scientific disciplines as genetics, biology, biochemistry, environmental physiology, biotechnology, bio-informatics, engineering, modelling and so forth. Novel cultivars, orchard designs and management regimes mean novel production targets and crop quality parameters. Produce quality and healthfulness have become the watch-words for market competitiveness.

In the European agriculture, research has thus become a multi-disciplinary enterprise with experts in many fields over a number of countries and in many facilities working in partnership with industry to translate results into development with extension applications in a cost-benefit framework. By instituting its six-fouryear 'frame programmes', the European Union (EU) has greatly stimulated this internationalization of research, as well as laying the groundwork for expert networking, private-public sector partnering and collegial collaboration benefiting all the EU's member-states, both old and new. Good examples of those who have reaped these benefits are countries like Italy, which have outstanding individual talents but little inclination to collaboration within big projects

While the importance of EU research is increasing, the resources of individual member-states are diminishing (agricultural faculties and research centres have been closed in some countries) and research itself suffers from an excess fragmentation (25 members and a hundred autonomous regions) that can result in resource waste. The EU, however, has decided to turn over a new leaf by supporting only broad-based projects covering equally broad and topical, not just economic, interests like the environment and nature, the life sciences, biotechnology, nanotechnology, multi-functional agriculture.

One current example the ISAFRUIT project (2006-10), the first, it is hoped, of a series in fruit industry that involves 60 of the EU's most accredited scientific institutions (but open to outside participation) working together after two years of planning and having a budget of almost $\bullet 10$ million (including public-sector cofinancing and private-sector partners). The project focuses on sustainable cropping systems, environmental physiology, genetics, biotechnology, bio-informatics, modelling and monitoring systems, and fruit quality to meet new consumer demands.

The EU is now drafting the next $7^{\text {th }}$ frame programme for 2007-2012 (with a total funds of 50 billion euro) that will cover several technological "platforms" sectors and at least two in agriculture, "Food for life" and "Plants for the future". The latter two will be a competing ground for world research as it is linked to global market trends as well as being driver by social concerns, public health issues, general wellbeing and proper use and conservation of natural resources. The fruit industry no longer wants to be singled out, even wrongly through disinformation, as a destabilising force of agro- and natural ecosystems, as the source of water-table and soil pollution, or of eutrophisation.

The fruit industry stands on the verge of global challenges increasingly focused on supply lines both of highly differentiated fresh products marked by quality, genuineness, flavour, tipicity, origin, new packaging, and of high-tech processed derivatives. Indeed, it will no longer be product price alone that decides the success and survival of the fruit industry and its growers. From now on the arbiters will also be food safety, pipeline traceability and transparency from field to market, label information, process or product trademarks, domestic and international certification. And, while trade barriers may come down, produce sanitary cordons may go up. The final decision, however, will rest with consumers everywhere, who have the right to choose the best for themselves, and it is to them that research must lend an ear.

The asymmetries among the world's leading producers, technological gaps and cost differences from country to country will continue for some time to obstacle greater trade liberalisation, as recent contrasts between the EU and the WTO underscore. Then too the less favourable climate conditions in northern growing districts are bound to gradually cede terrain to the warmer southern districts. All of this means that the more advanced economies must increasingly rely on innovation to remain competitive or just stay abreast and the developing countries must increasingly adhere to higher quality standards to keep their exports flowing. International cooperation will also need to be increased to upgrade of networking among researchers for projects targeted to shared objectives by exploiting synergies and complementary skills between countries of differing geographies and economic development. These efforts are to be aimed at securing adequate income from crops by increasing global supply throughout the year and enhancing quality levels via breeding to expand earliness and marketing calendars, e.g. using protected cropping wherever economics and prices permit.

Fruit is a valuable asset that improves people's nutrition and well-being. This means properly educating consumers beginning with the schools so people from childhood to adulthood and beyond will be in the habit of eating fruit. What we see, however, is statistics telling us that consumption is gradually diminishing because of life styles imposed by the workplace, over-pricing, and quality defects. These causes must be uprooted and consumption promoted, e.g. the $100-150 \mathrm{~kg} /$ year per capita of certain populations drops to less than $50 \mathrm{~kg} / \mathrm{year}$ in many countries levels low enough to undermine public health.

The enormous potential afforded by well-planned international research and development projects must be brought to harvest. Then too there are enormous possibilities being opened up in new areas biology (plant protection and organic farming), biotechnology applied to genetics and propagation, biochemistry (disease and input diagnostics, qualitative fruit analysis), and advances in physical-mechanical-electronic instruments (monitoring systems and precision tools) -all of which are part of IFP. Environmental physiology, to take another example, is an approach to deal with extension service issues like water and nutrient inputs, soil anomalies and leads to upgraded management practises and energy input savings.

Nor should we overlook GM plants, although lengthy experimentation is needed to censure safety and overcome consumer resistance. While the EU has weighed in against GMOs, it is foreseeable that they will resolve health and environmental problems that genetics cannot solve. Despite Europe's closed-door policy on GMOs (Italy enclosed), working groups there continue to press ahead in the field without recognition or the hope their results they have to date achieved with transgenic plants will be used in the near future. Every country should be able to exploit the best it has to offer on the international stage. Brazil, with its enormous farming potential that ranges from tropical to temperate districts, will definitely continue to play a leading role on the global stage, and not just within the fruit industry. 